\title{
Using the Internet to investigate consumer choice spaces
}

\author{
JANIS J. CROW and JAMES SHANTEAU \\ Kansas State University, Manhattan, Kansas \\ and \\ JOHN D. CASEY \\ University of Kansas, Lawrence, Kansas
}

\begin{abstract}
Traditional investigations of consumer choice processes include a matrix of alternatives described by attributes. The researcher-createdmatrix presents a product option space for the participant. In this article, we propose an alternative methodological approach to consumer choice processes. Specifically, we investigate choice processes when a participant creates his/her own product space. We describe a Web-based program and methodology used to collect data for three customizable products. Empirical results indicate that consumers are willing and able to make choices from their own product space. This research provides a new avenue for exploring choice processes.
\end{abstract}

Typically, when investigating consumers' choice processes, a researcher provides participants with a matrix of alternatives described by attributes. An investigator presents a combination of alternatives and attributes from which participants make a choice. For example, Product A is listed with $x_{1}^{a} \ldots x_{n}^{a}$ attributes, and Product B is listed with $x_{1}^{b} \ldots x_{n}^{b}$ attributes. The researcher then investigates the process by which consumers choose Product A or Product B.

\section{Consumer Choice Formats}

Methods to investigate choice processes have evolved over time. One early investigative tool, called information display boards, consisted of envelopes attached to a cardboard display (Jacoby, Chestnut, Weigl, \& Fisher, 1976; Payne, 1976). Each envelope contained a description of a product attribute for an alternative. With advances in computer technology, researchers could continually monitor the choice processes (Dahlstrand \& Montgomery, 1984).

One such computer program, Mouselab, displays an information board on a computer screen (Payne, Bettman, \& Johnson, 1993). In a typical Mouselab experiment, various options for apartments, listed as A, B, and C, might have the attributes of cost, size, and neighborhood, for example. Participants move a mouse over the cell containing alternative and attribute information, revealing apartment A's cost or C's size. On the basis of the mouse movements, the researcher evaluates how the subject makes a choice. The tracking of mouse movements has become a common tool for investigating consumer choice processes.

The authors thank the editor, Jonathan Vaughan, Richard Carlson, and an anonymous reviewer for their helpful comments on an earlier version of this paper. Correspondence should be addressed to J. J. Crow, Department of Marketing, Kansas State University, 201 Calvin Hall, Manhattan, KS 66506 (e-mail: jcrow@ksu.edu).
When choice processes are investigated in this way, the format of the information defines the product space. ${ }^{1}$ The researcher selects the alternatives and attributes. Thus, the investigation of choice processes is based on a researcherdefined product space. Given the restricted range of options, this may limit what we can learn about consumer choice processes. In particular, we do not know the consumer's ideal option.

The purpose of our current project is to allow consumers to create their own option(s). This allows us to address several questions: What kinds of options will consumers generate? What choice processes are involved when consumers generate their own product space? How would a consumer go about creating that space? These are the research questions that we wish to investigate.

\section{Product Customization}

When consumers customize products, they are creating a new product space. That is, participants select attributes to generate their desired alternative. When designing a custom-built computer to order, a consumer selects the memory size, hard drive, and so forth, on the basis of his/ her needs and desires.

The advent of computers and the Internet has given consumers the power to generate individualized options. Internet-based companies currently provide a wide range of customizable products and services ranging from breakfast cereals to zippers. At customatix.com, for example, consumers can customize a shoe by selecting the shoe style, color, and leather type.

However, researchers have yet to take advantage of the new opportunities to study such customized choices. In previous consumer choice investigations, the format was constrained by the technology available: cardboard or simple computer displays. Thus, the investigator provided the 
product space to the consumer. In the present study, these constraints are removed so that any product type is possible. In effect, the consumer reveals his/her product space to the researcher.

\section{A Web-Based Customization Program}

A special Web-based program was written to present stimuli, collect the data, and track individual participants' activity. The purpose of this section is to explain how the program operates. Readers are encouraged to contact the authors for details regarding implementing the program.

The program consists of a JavaScript servlet for the user interface and a relational database for data storage. Table 1 lists features and benefits. The program has two features that form a unique combination. ${ }^{2}$ The first is the ability to partition multiple stimuli into sections. Partitioning allows different operations to occur within a section. These operations can result in different actions. For example, in our study we created trial pages where participants could practice customizing a product. To create this feature, we identified predefined stimulus pages and the actions related to those pages (e.g., randomizing stimulus pages). This information was maintained in the configurationfile.

The second feature is the ability to randomly display stimuli. With the program, all of the stimuli can be randomized. Baron and Siepmann (2000) provide a discussion on how participants can allocate themselves to different versions of a Web study. This is not quite the same randomization process that we used, but it is similar in spirit. Our program created for each user a randomized list for the stimulus pages. When the user advanced through the study by requesting a page, the program sent the next page in the sequence. This procedure continued until all of the pages from the list were used.

Other features include the ability to authenticate users with a password and to maintain data continuity. Schmidt (2000) identified these features as helpful in Web-based research. Passwords restrict unauthorized users. Data continuity procedures provide the ability to monitor and track each participant's responses, thus ensuring reliable results.

For our study, when a participant accessed the Web site with a prespecified password, that user was given a unique numerical identifier that followed that individual throughout the study. This number allowed the participant's behavior to be tracked. For example, when a participant requests a page, the identity of the participant is confirmed, the page is sent, and the data are stored. Because of this uniqueidentifier, we could ensure that the participants were following the instructions, and, if necessary, we could incorporate stopping procedures to prohibit further access. For example, if participants did not complete the informed consent form, they were not allowed to proceed.

\section{An Empirical Investigation}

The customizable-product program was used to investigate two questions: (1) How does the amount of information (e.g., number of attributes) affect cognitive load? (2) What is the impact of providing starting values (e.g., by providing an attribute as a default)? Information overload has been found to influence consumer choice (Slovic, 1972), for example, by leading people to defer to default values (Tversky \& Shafir, 1992).

\section{METHOD}

\section{Participants}

A $3 \times 2 \times 2$ (product $\times$ attributes $\times$ default values) within-subjects repeated measures factorial design was used. Thirty-one participants customized three products (pizza, PDAs, and shoes) presented with 4 and 12 attributes. The products were displayed both with and without a default value for an attribute level. The participants selected the attribute level that suited their preference, thus creating their own product space.

\section{Stimulus}

The participants customized products on a Web site modeled after electronic commerce websites. Figure 1 shows the stimulus page for customizing athletic shoes with a high number of attributes and the default attribute level provided. A participant receiving this page would customize each attribute. For example, when customizing the shoe color, one would choose the default-in this case red-or select from the list of other available colors. In the nondefault mode, the attribute level would display the words "Select one," and the participant would choose from the available list. After customizing each product, the participants answered two questions: (1) How likely were they to purchase the product they created, and (2) How difficult was it to customize the product? ${ }^{3}$

Table 1

Features and Benefits of Program

\begin{tabular}{ll}
\hline \multicolumn{1}{c}{ Features } & \multicolumn{1}{c}{ Benefits } \\
\hline Partitions & Experiment can be sectioned into partitions with different operations in sections. \\
Randomization & Complete randomization by study or section allows for repeated measures. \\
Authentication & $\begin{array}{l}\text { Only authorized users can access system. } \\
\text { Users' completed/not completed pages can be tracked. }\end{array}$ \\
& Authorized users are restricted to only one contribution per stimulus page. \\
Data continuity procedures & Participants cannot change answers to previously submitted questions. \\
Nonrecordable stimuli & Trial pages can be used as practice without interfering with data collection. \\
Data storage & Responses are stored in database for further analysis. \\
Stopping procedures & Experiments can be curtailed or suspended if the form is not correctly completed.
\end{tabular}




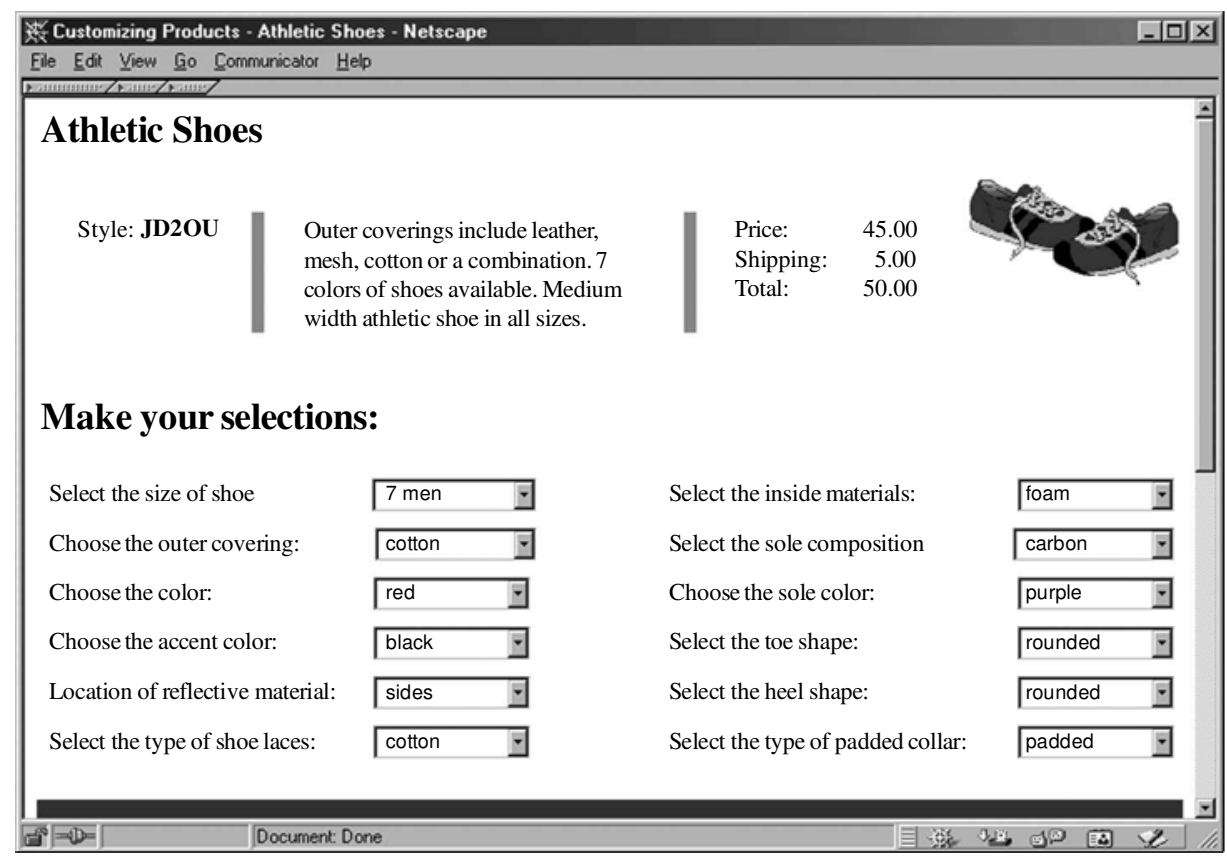

Figure 1. Athletic Shoes, high attribute level in default mode.

\section{RESULTS}

The results of the ratings indicate that the participants were more likely to purchase a customizable product with a high number of attributes $(M=43.09, S E=2.25)$ as opposed to a low number $(M=35.91, S E=2.22)[F(1,30)=$ $10.33, p<.005]$. The participants found it less difficult with a default value $(M=10.63, S E=1.06)$ than with a nondefault value $(M=13.31, S E=1.21)[F(1,30)=4.92$, $p<.005]$. In addition, the participants found it more difficult to customize a high number of attributes $(M=$ $17.49, S E=1.53)$ than a low number of attributes $(M=$ $6.46, S E=0.74)[F(1,30)=83.64, p<.005]$. There was no effect of providing a default value on the likelihood of purchasing.

\section{DISCUSSION}

In this study, we found that participants were comfortable making choices from their own product space. The ratings for difficulty in customizing were low. The highest mean rating was 17.49 out of 100 , with $S E=1.53$. Nearly all of the volunteers completed the study. In addition, it appears that they enjoyed the process. The participants' comments indicated that they liked customizing their products. We would suggest this procedure as a natural method in making a choice. As the Internet evolves, we will see more decisions made on line. It is important to understand the effect of this new environment on the making of choices.

The program provides a user interface with flexibility and support for variety of research topics. It presents in- formation in a Web-based format, which of course is becoming more and more familiar to consumers. For the researcher, it permits flexibility in the presentation of different types of stimuli with different operations. The program also manages data collection and storage. The researcher can then export the data to a statistical software program for analysis.

Investigating choice processes with this program goes beyond current methods. This study reveals that Internet technology provides a new way of looking at choice processes. In the past, researchers were able to investigate only static alternatives with prespecified attributes. This study demonstrates a new way of conducting research on choices. Customizing products is one such example.

Furthermore, this Web-based program allows us to ask some intriguing questions. In studying choices, we can determine the consumer's choice space. Specifically, we could investigate the limitations in creating product space or factors influencing customizing, for example. Research along these lines might enhance our understanding of choice processes as well other areas of psychology. For example, the program could be used to investigate memory processes when multiple stimuli are presented. It could be used to present stimuli testing perceptual phenomena. These are some examples of broad areas of psychology in which this program could be useful. Finally, because this is a Web-based program, the opportunity is available to broadly investigate other populations (e.g., children) or those with special needs or circumstances. No matter what domain, taking advantage of technology will further our understanding of human behavior. 


\section{REFERENCES}

Baron, J., \& Siepmann, M. (2000). Techniques for creating and using Web questionnaires in research and testing. In M. Birnbaum (Ed.), Psychological experiments on the Internet (pp. 235-265). San Diego: Academic Press.

Birnbaum, M. (2000). Psychological experiments on the Internet. San Diego: Academic Press.

Dahlstrand, U., \& Montgomery, H. (1984). Information search and evaluative processes in decision making: A computer based process tracing study. Acta Psychologica, 56, 112-123.

Jacoby, J., Chestnut, R. W., Weigl, K.C., \& Fisher, W. (1976). Prepurchase information acquisition: Description of a process methodology, research paradigm and pilot investigation. In B. B. Anderson (Ed.), Advances in consumer research 3 (pp. 306-314). Chicago: Association for Consumer Research.

PAYNe, J. W. (1976). Task complexity and contingent processing in decision making: An information search and protocol analysis. Organizational Behavior \& Human Performance, 16, 366-387.

Payne, J. W., Bettman, J. R., \& Johnson, E. J. (1993). The adaptive decision maker. New York: Cambridge University Press.
ScHmidT, W. C. (2000). The server side of psychology Web experiments. In M. Birnbaum (Ed.), Psychological experiments on the Internet (pp. 285-310). San Diego: Academic Press.

SLovic, P. (1972). From Shakespeare to Simon: Speculations and some evidence about man's ability to process information. ORI Research Monographs, 12(2).

Tversky, A., \& Shafir, E. (1992). Choice under conflict: The dynamics of deferred decision. Psychological Science, 3, 358-361.

\section{NOTES}

1. Conceivably, this space is equivalent to products available.

2. Each of the features has been used separately in previous Webbased experiments (Birnbaum, 2000). However, providing these features in a single program provides new opportunities for the researcher.

3. Participants rated customizing their products from 0 (not likely to purchase) to 100 (likely to purchase) and 0 (not very difficult) to 100 (very difficult).

(Manuscript received January 7, 2003; revision accepted for publication March 9, 2003.) 